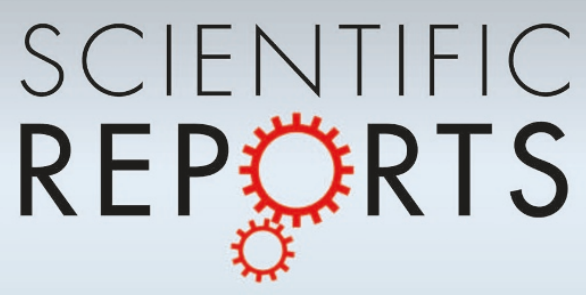

OPEN

SUBJECT AREAS:

ENVIRONMENTAL

SCIENCES

ATMOSPHERIC CHEMISTRY

Received

20 January 2014

Accepted

22 April 2014

Published

12 May 2014

Correspondence and requests for materials should be addressed to W.G.W. (wangwg@ iccas.ac.cn) or M.F.G. (gemaofa@iccas.ac. cn)

\section{Optical properties of secondary organic aerosols generated by photooxidation of aromatic hydrocarbons}

\author{
Kun Li', Weigang Wang' ${ }^{1}$ Maofa Ge' , Jiangjun Li \& Dong Wang ${ }^{2}$
}

\begin{abstract}
'State Key Laboratory for Structural Chemistry of Unstable and Stable Species, Beijing National Laboratory for Molecular Sciences (BNLMS), Institute of Chemistry, Chinese Academy of Sciences, Beijing, 100190, P. R. China, ${ }^{2}$ Key Laboratory of Molecular Nanostructure and Nanotechnology, Institute of Chemistry, Chinese Academy of Sciences (CAS), Beijing 100190, P. R. China.
\end{abstract}

The refractive index (RI) is the fundamental characteristic that affects the optical properties of aerosols, which could be some of the most important factors influencing direct radiative forcing. The secondary organic aerosols (SOAs) generated by the photooxidation of benzene, toluene, ethylbenzene and $m$-xylene (BTEX) under low- $-\mathrm{NO}_{\mathrm{x}}$ and high- $\mathrm{NO}_{\mathrm{x}}$ conditions are explored in this study. The particles generated in our experiments are considered to be spherical, based on atomic force microscopy (AFM) images, and nonabsorbent at a wavelength of $532 \mathrm{~nm}$, as determined by ultraviolet-visible light (UV-Vis) spectroscopy. The retrieved RIs at $532 \mathrm{~nm}$ for the SOAs range from 1.38-1.59, depending on several factors, such as different precursors and $\mathrm{NO}_{\mathrm{x}}$ levels. The RIs of the SOAs are altered differently as the $\mathrm{NO}_{\mathrm{x}}$ concentration increases as follows: the RIs of the SOAs derived from benzene and toluene increase, whereas those of the SOAs derived from ethylbenzene and $m$-xylene decrease. Finally, by comparing the experimental data with the model values, we demonstrate that the models likely overestimate the RI values of the SOA particles to a certain extent, which in turn overestimates the global direct radiative forcing of the organic particles.

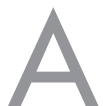

erosol particles could affect the global radiative balance of the atmosphere ${ }^{1-4}$, but the effects remain poorly quantified $^{5}$. In contrast to other methods of quantifying scattering and absorption, the refractive index (RI) depends primarily on composition rather than particle size or concentration ${ }^{6}$; therefore, it is an important and useful characteristic. Using the RI, secondary quantities, such as the absorption and scattering cross sections, can be calculated. Globally, organic compounds compose $50 \%$ of the aerosol mass, and in certain polluted areas, this amount can be as high as $90 \%^{7}$. Secondary organic aerosols (SOAs) compose up to $80 \%$ of all organic aerosols and contribute to the attenuation of regional visibility, climate change and potential health hazards ${ }^{8-10}$. Considering the ubiquity and predominance of SOAs, understanding the optical properties of SOAs is of great concern. Aromatic hydrocarbons compose $20-50 \%$ of the non-methane hydrocarbons in urban air and are considered to be some of the primary precursors to urban $\mathrm{SOAs}^{11}$. Anthropogenic aromatic compounds yield $76 \%$ of the calculated secondary organic particles in Beijing City and are thought to be the major source of SOAs, while among the aromatic hydrocarbons, benzene, toluene and the $\mathrm{C} 8$ aromatics (e.g., xylene and ethylbenzene) are the most abundant species ${ }^{12}$. The $\mathrm{NO}_{\mathrm{x}}$ level in the atmosphere is variable. In different regions (e.g., urban, suburban and rural areas or polluted areas and relatively clean areas) and during different periods (e.g., morning, midday and afternoon), the $\mathrm{NO}_{\mathrm{x}}$ concentration may change acutely, ranging from $\leq 2 \mathrm{ppb}$ to several hundred $\mathrm{ppb}^{13-15}$, and the level of $\mathrm{NO}_{\mathrm{x}}$ has been found to be highly influential in SOA formation from a variety of compounds ${ }^{16-19}$. Therefore, the investigation of different $\mathrm{NO}_{\mathrm{x}}$ levels is imperative and has great atmospheric significance.

Many previous studies have been performed on the gas-phase photooxidation of aromatic hydrocarbons. These studies have primarily concentrated on the reaction mechanisms, SOA yields and particle composition, but the optical properties of the SOAs are not well understood ${ }^{20}$. Recently, certain studies have been performed to investigate the optical properties of SOA particles ${ }^{21-27}$, primarily focusing on $\alpha$-pinene and toluene, which represent biological and anthropogenic volatile organic compounds (VOCs), respectively. Nakayama et al. measured the RIs at 355 and $532 \mathrm{~nm}$ of toluene and $\alpha$-pinene SOAs in the presence of $\mathrm{NO}_{\mathrm{x}}$ or $\mathrm{O}_{3}$ and found values ranging from 1.46 to $1.63^{21}$. These authors have further investigated the optical properties of the SOAs derived from toluene and 1,3,5-trimethylbenzene at wavelengths of 405, 532 and $781 \mathrm{~nm}$ and have found that nitroaromatic compounds are the major contributors to the light absorption of the toluene SOA at UV wave- 
lengths ${ }^{22}$. Redmond and Thompson estimated the RIs of $\alpha$-pinene and toluene SOAs and found values of 1.49-1.51 and 1.49-1.50, respectively ${ }^{23}$. Kim et al. have reported the RIs for the SOAs generated by $\alpha$-pinene, $\beta$-pinene and toluene under high or low $\mathrm{NO}_{\mathrm{x}}$ conditions. The RIs varied from 1.45 to 1.6 , depending on the precursor and aerosol mass concentration ${ }^{24}$. Recently, Kim and Paulson investigated the relative volatility of SOAs by evaporating organics from the particles using a thermo denuder at temperatures between 60 and $100^{\circ} \mathrm{C}$ and measured the RIs before and after evaporation; they observed no change in the RI value of the toluene SOA during this process $^{26}$.

Although the optical properties of the SOAs generated from different aromatic hydrocarbons have significant atmospheric implications, these characteristics are unclear ${ }^{22}$. This study focuses on the optical properties of the SOAs formed by benzene, toluene, ethylbenzene and $m$-xylene (BTEX), all of which are typical anthropogenic VOCs. We investigate the RIs of these SOA particles under low- $\mathrm{NO}_{\mathrm{x}}$ and high- $\mathrm{NO}_{\mathrm{x}}$ conditions (classical and $\mathrm{HONO}$ ) to determine the influence of the $\mathrm{NO}_{\mathrm{x}}$ level (see Methods). The $\mathrm{NO}_{\mathrm{x}}$ level in the high $-\mathrm{NO}_{\mathrm{x}}$ condition is close to that in the existing atmosphere ${ }^{13,14}$, and the $\mathrm{HC} / \mathrm{NO}_{\mathrm{x}}$ ratio in the $\mathrm{HONO}$ experiments is very similar to ambient values ${ }^{28-30}$, whereas the low- $\mathrm{NO}_{\mathrm{x}}$ experiments represent certain extreme conditions wherein the $\mathrm{NO}_{\mathrm{x}}$ level is $\leq 2 \mathrm{ppb}^{15,30-32}$. The morphology of the particles was also determined in this study. To our knowledge, this is the first investigation of the RIs of the SOAs derived from benzene, ethylbenzene and $m$ xylene and the first determination of the influence of the $\mathrm{NO}_{\mathrm{x}}$ level on these SOAs. Finally, a comparison between the model values and the experimental data is presented, and a suggestion for the revision of the model RI values is given.

\section{Results}

SOA formation process and features. As illustrated in Fig. 1, three different $\mathrm{NO}_{\mathrm{x}}$ conditions were investigated, the details of which are given in the Methods section. Fig. 1a displays a typical reaction profile under the low- $\mathrm{NO}_{\mathrm{x}}$ condition. In this experiment, the initial $m$-xylene and $\mathrm{H}_{2} \mathrm{O}_{2}$ concentrations were $200 \mathrm{ppb}$ and $5 \mathrm{ppm}$, respectively. During the entire process, $121.4 \mathrm{ppb} \mathrm{m}$-xylene was consumed. The particles were generated just within a few minutes after the lights were turned on. A small amount of $\mathrm{O}_{3}(<20 \mathrm{ppb})$ was produced during this reaction. After more than 4 hours of illumination, the particle size tended to be stable at approximately $200 \mathrm{~nm}$, and the mass concentration (M) was approximately $350 \mu \mathrm{g} /$ $\mathrm{m}^{3}$ after a wall-loss correction using the method introduced by McMurry and Grosjean ${ }^{33}$. The SMPS data (M) in Fig. 1 shows that the mass concentration plateaued at the end of the experiment, indicating that the status in the chamber tend to stabilize. Fig. $1 \mathrm{~b}$ shows a representative reaction profile under the classical high- $\mathrm{NO}_{\mathrm{x}}$ condition. In this experiment, the initial ethylbenzene, $\mathrm{NO}$ and $\mathrm{NO}_{2}$ concentrations were $4 \mathrm{ppm}, 3 \mathrm{ppb}$ and $480 \mathrm{ppb}$, respectively. During the photooxidation, $402 \mathrm{ppb}$ ethylbenzene was reacted. No particles were generated during the first 2.5 hours. Particles appeared just as the NO concentration approached zero, which is consistent with other classical high- $\mathrm{NO}_{\mathrm{x}}$ studies ${ }^{16,19,34}$. At the end of the experiment, the particle surface mean diameter was approximately $300 \mathrm{~nm}$, and the mass concentration was greater than $40 \mu \mathrm{g} / \mathrm{m}^{3}$. A considerable amount of $\mathrm{O}_{3}$ was generated during the reaction process, especially after particles were generated, leading to a high concentration of greater than $300 \mathrm{ppb}$ when the reaction was complete. Fig. 1c is the reaction profile of a HONO experiment. The initial $m$-xylene, $\mathrm{NO}$ and $\mathrm{NO}_{2}$ concentrations were $200 \mathrm{ppb}$, $442 \mathrm{ppb}$ and $465 \mathrm{ppb}$, respectively. During the entire process, $117.2 \mathrm{ppb} m$-xylene was consumed, yielding approximately $400 \mu \mathrm{g}$ of secondary particles. Aerosol generation occurred almost immediately, even when the NO concentration was high. The final size mode was approximately $450 \mathrm{~nm}$, which was significantly larger than with the other two conditions. Because the NO concentration was high, the formation of $\mathrm{O}_{3}$ was restrained ${ }^{19}$.

Morphology of the secondary particles. In the Mie theory, it is assumed that the aerosol particles are spheres. Under this premise, the RIs derived according to the Mie theory are correct and accurate; otherwise, a deviation will occur. Therefore, we investigated the morphology of the SOA particles. An atomic force microscopy (AFM) image of a typical aromatic SOA is shown in Fig. 2. The SOA was generated by the photooxidation of ethylbenzene under a low- $\mathrm{NO}_{\mathrm{x}}$ condition. Most of the particles are less than $1 \mu \mathrm{m}$ and are approximately $600-800 \mathrm{~nm}$ in diameter. The cross-section data of a typical particle are also depicted in Fig. 2. The height of this particle is approximately $70 \mathrm{~nm}$, whereas the width (diameter) is greater than $600 \mathrm{~nm}$; therefore, its shape is similar to a pie. We speculate that the particles were liquid-like droplets when they were suspended in the air and became flattened upon impact with the wafers. This speculation is consistent with certain other studies. Freedman et al. have found that organic particles deform upon impact with a surface $^{35}$, which is similar to our observation. Marcolli et al. have noted that the SOA particles should be liquid or waxy ${ }^{36}$. Bahreini et al. have suggested that the SOA formed via cycloalkene ozonolysis is likely in the liquid phase ${ }^{37}$. In this study, our investigation found that the SOA particles formed from BTEX photooxidation are likely in a liquid state at ambient temperature and pressure.

The volume of the pie-like particle was calculated, which allowed calculation of the equivalent diameter when it was a sphere. We assumed that the particles were spheres because the surface tension of the droplets would minimise their surface. The equivalent diameter of the particle we chose in Fig. 2 was $200 \mathrm{~nm}$. We found that most of the particles were similar in size to the selected particle, which is consistent with the diameter data of the scanning mobility particle sizer (SMPS), approximately $200 \mathrm{~nm}$. The AFM images thus suggest that the particles are likely to be spherical droplets; therefore, there is likely to be little deviation when using the Mie theory.

Light absorption of the SOA particles. The light absorption of SOAs at visible wavelengths has been investigated and reported by many researchers in laboratory and field studies ${ }^{3-40}$. Glyoxal, methylglyoxal and related compounds can form light-absorbing substances during aqueous reactions, which could contribute to atmospheric brown carbon $^{41,42}$. Photochemical experiments with phenol and related compounds in the aqueous phase have revealed a shift in the absorption to longer wavelengths (from 350 to $650 \mathrm{~nm})^{43,44}$. The evolution of the absorption to longer wavelengths has been explained by the formation of larger conjugated oligomers that exhibit soot-like structures, whereas these types of structures may not be formed in the gas phase in an oxygencontaining atmosphere ${ }^{45}$. Certain biogenic VOCs, such as limonene and isoprene, can also form light-absorbing SOAs in the presence of acid seeds or aqueous ammonium ions ${ }^{46,47}$. At the same time, some researchers have found that certain types of SOAs formed by gas-phase oxidation in the absence of seeds have no significant absorption in the visible range $e^{21,22,48,49}$. Liu et al. have investigated the light absorption of SOAs formed by the gas-phase oxidation of $\alpha$-pinene, limonene and catechol from 220 to $1200 \mathrm{~nm}$ and have found negligible absorption in the visible range ${ }^{48}$. Song et al. have studied the gas-phase oxidation of $\alpha$-pinene $+\mathrm{O}_{3}$ and $\alpha$-pinene $+\mathrm{NO}_{\mathrm{x}}+\mathrm{O}_{3}$ systems and have concluded that these systems do not form visible light-absorbing SOAs under typical atmospheric conditions ${ }^{49}$. Our results are consistent with these studies. From the light-absorption spectrum over the range of 300-700 $\mathrm{nm}$ (see Supplementary Fig. S2 online), we can observe that gas-phaseformed BTEX SOAs absorb light at wavelengths $<450 \mathrm{~nm}$ but have no obvious absorption at $532 \mathrm{~nm}$ with the detection sensitivity of our instrument. In other words, only the scattering properties of the secondary particles generated by the gas-phase 

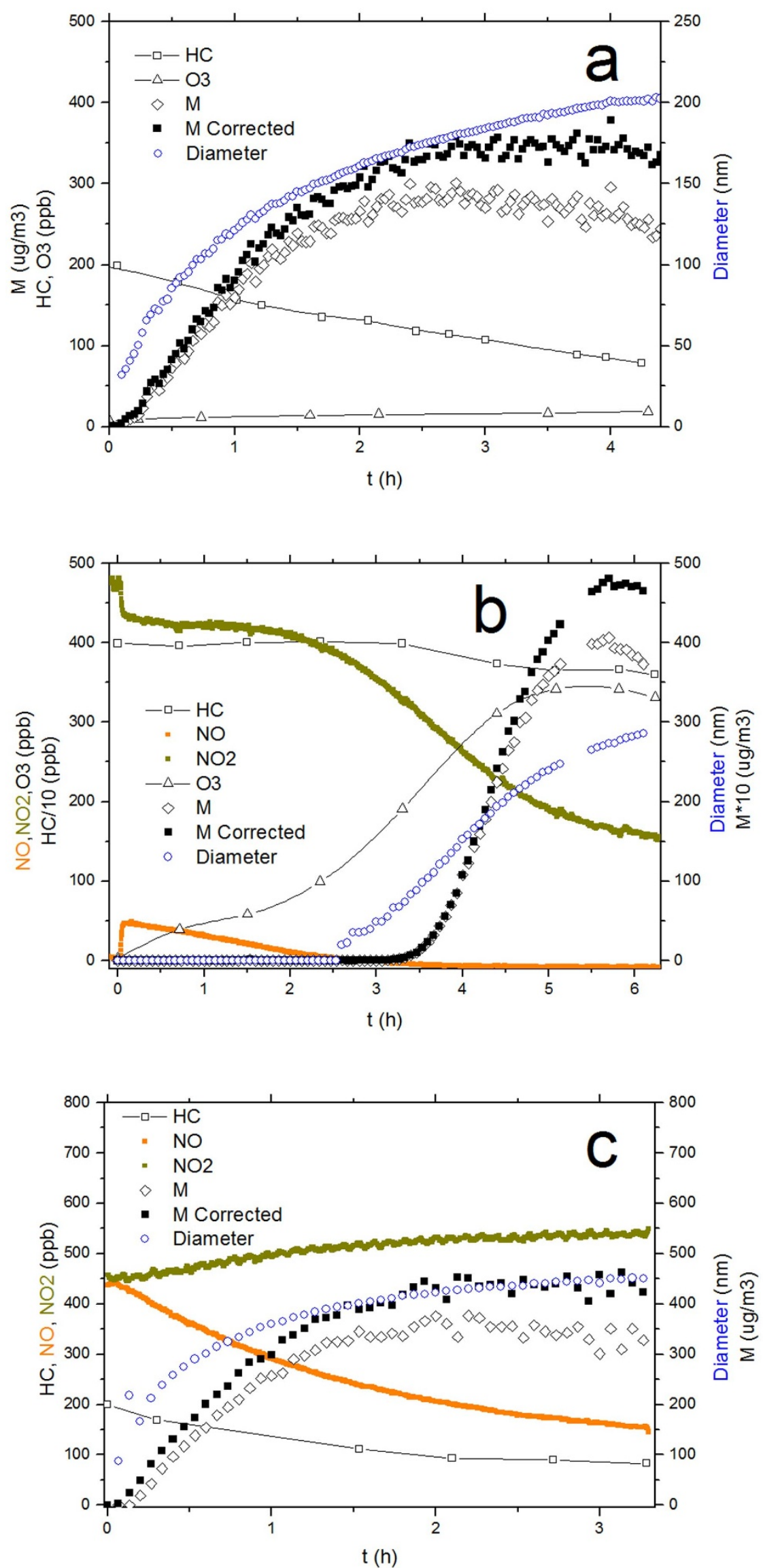

Figure $1 \mid$ Reaction profiles. (a) The low- $\mathrm{NO}_{\mathrm{x}}$ experiment (200 ppb $m$-xylene, $5 \mathrm{ppm} \mathrm{H}_{2} \mathrm{O}_{2}$ ); (b) the classical high- $\mathrm{NO}_{\mathrm{x}}$ experiment $(4$ ppm ethylbenzene, 3 ppb NO and 480 ppb NO 2 ); (c) the HONO experiment (200 ppb $m$-xylene, 442 ppb NO and $465 \mathrm{ppb} \mathrm{NO}_{2}$ ). 


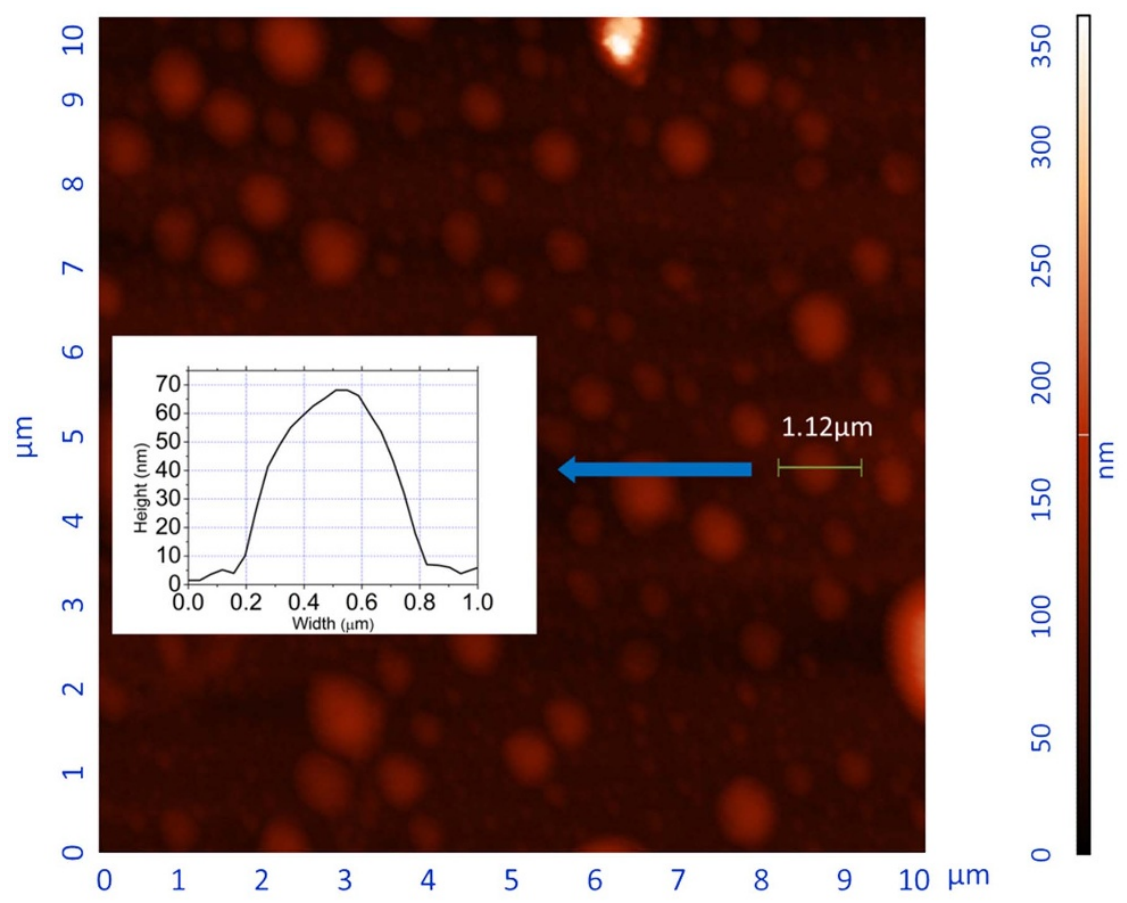

Figure 2 AFM image of the SOA particles formed by photooxidation of aromatic hydrocarbons (typically, $200 \mathrm{ppb}$ ethylbenzene, $5 \mathrm{ppm} \mathrm{H} 2 \mathrm{O} 2$ ).

reaction in our experiments should be considered, and the value of $k$ in the RI equation $(m=n+k i)$ can be ignored.

RI under different $\mathrm{NO}_{\mathbf{x}}$ levels. The extinction efficiency at each particle size can be calculated for a given value of $\mathrm{n}$ and $\mathrm{k}$ using a Mie code written in MATLAB for spherical particles, based on the FORTRAN code from Bohren and Huffman ${ }^{50}$. The calculated total extinction is then compared to the measured extinction. The best-fit $\mathrm{RI}$ is determined by minimising the following reduced merit function $\left(\chi_{r}\right)$ :

$$
\chi_{r}=\frac{1}{N} \sum_{i=1}^{N}\left(Q_{\text {ext, measured }}-Q_{\text {ext, } \text {,calculated }}(n, k)\right)_{i}^{2}
$$

where $N$ is the number of diameters to calculate, $Q_{\text {ext }}$ is the extinction efficiency of the particles (see Methods) and $n$ and $k$ denote the real and imaginary parts of the RI, respectively.

Fig. 3a depicts the dependence of $Q_{\text {ext }}$ on the surface mean diameter and the retrieved RIs of the BTEX SOAs under the low- $\mathrm{NO}_{\mathrm{x}}$ condition. The concentrations of hydrocarbon and oxidant are identical. The temperature and relative humidity $(\mathrm{RH})$ conditions are similar (with a fluctuation of $<2{ }^{\circ} \mathrm{C}$ and $<4 \% \mathrm{RH}$, respectively). As illustrated in the figure, the measured extinction efficiencies generally conform to the Mie scattering curves, and the RI values are in the range of 1.45-1.52. Studies that explore the RIs of these four aromatic hydrocarbons under low- $\mathrm{NO}_{\mathrm{x}}$ conditions are lacking; therefore, only limited data can be contrasted. Note that the $m$-xylene SOA has the largest RI value at 1.52 , followed by the ethylbenzene SOA at 1.478, the benzene SOA at 1.464 and the toluene SOA, which has the smallest $\mathrm{RI}$ value at 1.45 . It is well known that hydrocarbons react with $\mathrm{OH}$ to produce $\mathrm{RO}_{2}$, and the $\mathrm{RO}_{2}$ can then react with $\mathrm{HO}_{2}$, $\mathrm{NO}$ and $\mathrm{RO}_{2}{ }^{51}$. Under this condition, there is no detectable $\mathrm{NO}$; therefore, we can attribute these RI values to the RIs of the BTEX SOAs generated through the $\mathrm{RO}_{2}+\mathrm{RO}_{2}$ and $\mathrm{RO}_{2}+\mathrm{HO}_{2}$ pathways. The different $\mathrm{RI}$ values are attributed to the different components of the products. Although undergoing similar reaction pathways under the low- $\mathrm{NO}_{\mathrm{x}}$ condition, $m$-xylene tends to produce products with high RI values. The data also reveal that the benzene SOA particles are smaller in size than the other particles, leading to markedly smaller final extinction efficiencies. This result is likely due to the different structure of the precursors. With no alkyl group attached to the benzene ring, benzene is less reactive than the other alkyl-substituted aromatics ${ }^{34}$.

The retrieved RI values and the dependence of the extinction efficiencies on the surface mean diameter of the BTEX SOAs under the classical high $-\mathrm{NO}_{\mathrm{x}}$ condition are shown in Fig. 3b. Fig. $3 \mathrm{c}$ represents the HONO experiments for toluene and $m$-xylene; benzene and ethylbenzene do not produce detectable particles under this condition. The RI values are in the range of 1.406-1.518. In a classical high- $\mathrm{NO}_{\mathrm{x}}$ experiment with toluene, Kim et al. measured a range of 1.4-1.6 for the high- $\mathrm{NO}_{\mathrm{x}}$ toluene $\mathrm{SOA}^{24}$; Nakayama et al. measured this $\mathrm{RI}$ value at $1.483 \pm 0.036^{21}$. We measure 1.464 for this RI value, which agrees well with previous studies. We notice that the RI value of the classical high- $\mathrm{NO}_{\mathrm{x}} \mathrm{SOA}$ ranges from 1.464 to 1.496 , which is a narrower range than in the low- $\mathrm{NO}_{\mathrm{x}}$ condition. The $\mathrm{RI}$ values of the SOAs generated from different aromatic hydrocarbons respond differently when the $\mathrm{NO}_{\mathrm{x}}$ level increases from low to high as follows: the RIs of SOAs generated from benzene and toluene oxidation increase, whereas the RIs of the ethylbenzene and $m$-xylene SOAs decrease. Unexpectedly, the toluene and $m$-xylene SOA particles have the same $\mathrm{RI}$ value under the classical high- $\mathrm{NO}_{\mathrm{x}}$ condition, whereas the RI values are clearly different in the HONO experiment. We infer that the $\mathrm{RO}_{2}+\mathrm{NO}$ pathway is likely to play an important role in leading to this result because the NO concentration in the HONO experiment is significantly higher (Fig. 1b, c). The details of this phenomenon will be discussed in the following section.

Changes in the RIs as the particles grow. Certain previous studies have assumed that the RI values of the SOA particles remain constant as the particles grow ${ }^{21,22}$; however, in our experiment (as shown in Fig. 3), certain data points do not fit well with the extinction curves using the uniform RI value. Therefore, we retrieve the RI for every point. The results in Fig. 4 indicate that the products of different aromatic hydrocarbons display different trends as the particle size increases, and the details are described below. For the benzene SOA, the RI values slightly increase as the diameter increases under both the low and high $\mathrm{NO}_{\mathrm{x}}$ levels, with the high- $\mathrm{NO}_{\mathrm{x}}$ condition higher than the low- $\mathrm{NO}_{\mathrm{x}}$ condition. For the toluene SOA, the RI values 

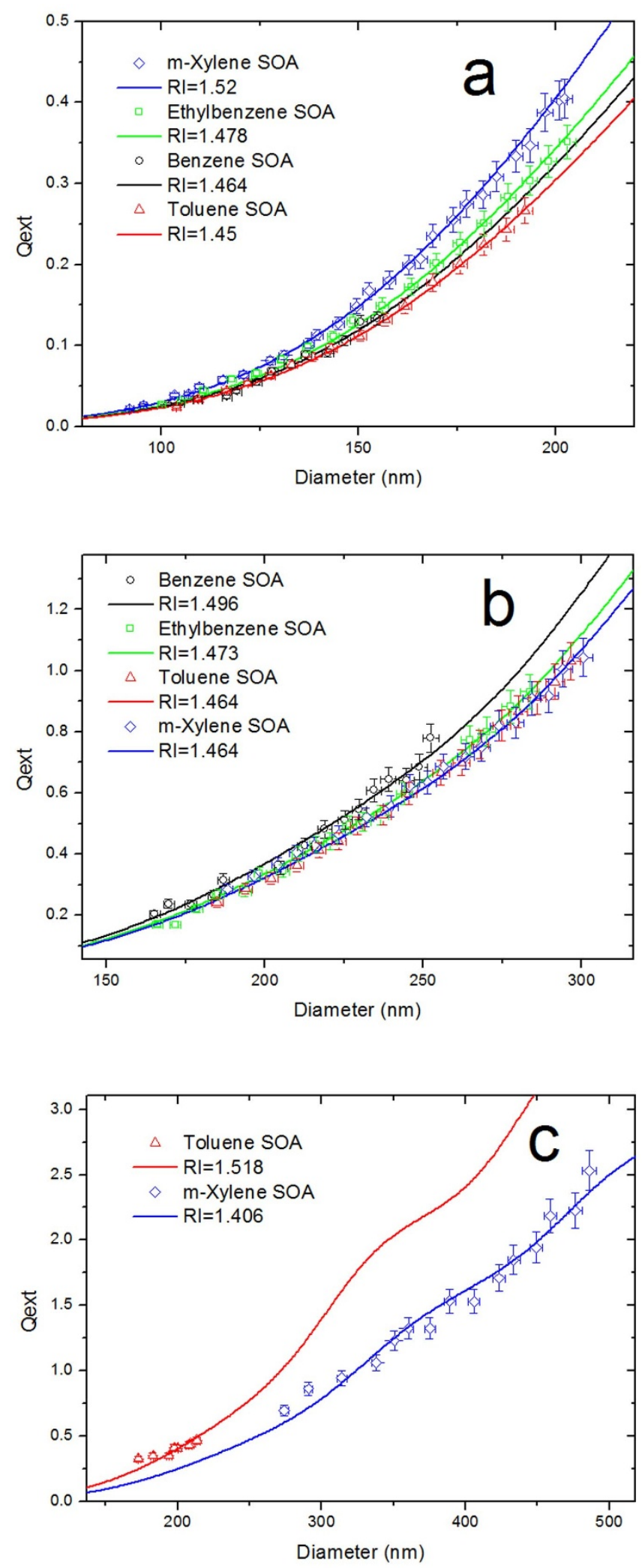

Figure 3 Dependence of the extinction efficiencies of the polydispersed SOA particles on the surface mean diameter at a wavelength of $532 \mathrm{~nm}$ and the retrieved RIs for the following. (a) the L1, L2, L5 and L7 low- $\mathrm{NO}_{\mathrm{x}}$ experiments; (b) the classical high- $\mathrm{NO}_{\mathrm{x}}$ experiments; (c) the $\mathrm{HONO}$ experiments. change slightly under the low and high $\mathrm{NO}_{\mathrm{x}}$ levels, with the high $\mathrm{NO}_{\mathrm{x}}$ condition being slightly higher, but the SOA under the HONO condition gives a significantly higher RI value with a decreasing trend. For the ethylbenzene SOA, the RI values have a decreasing trend as the particles grow under the low- $\mathrm{NO}_{\mathrm{x}}$ condition and do not show any clear change under the high- $\mathrm{NO}_{\mathrm{x}}$ condition. The most obvious phenomenon of fluctuation occurs for the $m$-xylene SOA with decreasing RI values as the particles grow and the $\mathrm{NO}_{\mathrm{x}}$ level increases. Changing RI values have also been observed in other studies on certain biogenic $\mathrm{SOAs}^{24-26}$, indicating that the RI values are not constant.

We infer that the products of the $\mathrm{RO}_{2}+\mathrm{NO}$ pathway with BTEX precursors have different optical properties, leading to the results in Fig. 4. As we mentioned in the previous section, the reaction pathways of the low- $\mathrm{NO}_{\mathrm{x}}$ experiments are $\mathrm{RO}_{2}+\mathrm{RO}_{2}$ and $\mathrm{RO}_{2}+\mathrm{HO}_{2}$, whereas for the high- $\mathrm{NO}_{\mathrm{x}}$ experiments, the $\mathrm{RO}_{2}+\mathrm{NO}$ pathway is added to compete with the other two pathways. Fig. 3a shows the optical properties of the products of the $\mathrm{RO}_{2}+\mathrm{RO}_{2}$ and $\mathrm{RO}_{2}+\mathrm{HO}_{2}$ pathways, whereas the difference between Fig. $3 \mathrm{~b}$ and Fig. $3 \mathrm{a}$ is possibly caused by the different optical properties of the $\mathrm{RO}_{2}+$ NO products compared with the former two pathways. For the data shown in Fig. 3c, the proportion of the $\mathrm{RO}_{2}+\mathrm{NO}$ pathway is larger than in Fig. $3 \mathrm{~b}$ because the NO concentration is significantly higher during the photooxidation process; in Fig. 4, this trend is much clearer. The $\mathrm{RI}$ values of the $\mathrm{RO}_{2}+\mathrm{NO}$ pathway products can be placed in order, taking the low- $\mathrm{NO}_{\mathrm{x}} \mathrm{RI}$ values as the baseline. The order is as follows: benzene (higher than the baseline) $>$ toluene (slightly higher than the baseline) $>$ ethylbenzene (slightly lower than the baseline) $>m$-xylene (significantly lower than the baseline). The HONO experiments agree well with this order, as shown in Fig. $4 \mathrm{~b}$ and $4 \mathrm{~d}$. For the toluene SOA, the HONO experiments (higher $\mathrm{NO}$ ) yield a higher RI value, whereas for the $m$-xylene SOA, the HONO experiments yield a lower RI value. The different performance of BTEX under the high- $\mathrm{NO}_{\mathrm{x}}$ condition is likely due to the different molecular structures of the hydrocarbons, and the details of these differences should be studied in future research.

To quantitatively compare the measured RIs with the composition measured by Forstner et al..$^{52}$, we calculate the RIs for the SOA components with a quantitative structure-property relationship (QSPR) approach, as developed by Redmond and Thompson ${ }^{23}$. The results are depicted in Fig. 4. The QSPR was built with the $589 \mathrm{~nm}$ data, whereas our measurements were made at $532 \mathrm{~nm}$; however, this difference has little influence because the RIs of organic materials have only a very slight dependence on the wavelength in the mid-visible range, changing by less than $0.002-0.005$ between 589 and $532 \mathrm{~nm}^{53}$. We observe that there are certain deviations between the experimental data and the calculated values. Because Forstner et al. identified only $15-30 \%$ of the collected aerosol mass, and several identified compounds were thought to be vapour adsorption to the quartz filter rather than aerosol-phase constituent ${ }^{52}$, the deviations are reasonable. In addition, the deviations may be caused by the different experimental conditions, such as the addition of propene, the light type and intensity, the temperature and the RH. Under different initial conditions, the components of the products may change.

We notice that the RI value of the $m$-xylene SOA has a significant fluctuation. This phenomenon may be attributed to the following reasons. Initially, the density variation may change the RI values. Commonly, there is a positive correlation between the RI and the density. A denser material generally tends to have a larger $\mathrm{RI}^{54}$. From certain earlier studies ${ }^{55,56}$, we know that the $m$-xylene SOA obtains a higher density at the onset of aerosol formation, and the density decreases as the particles become larger; the decreasing density leads to the decrease in the RIs, and another name for the RI is optical density $^{54}$. The second explanation for the fluctuation is heterogeneous reaction and the ageing process. Aromatics react with $\mathrm{OH}$ radicals in the gas phase and produce multifunctional carbonyls that have 

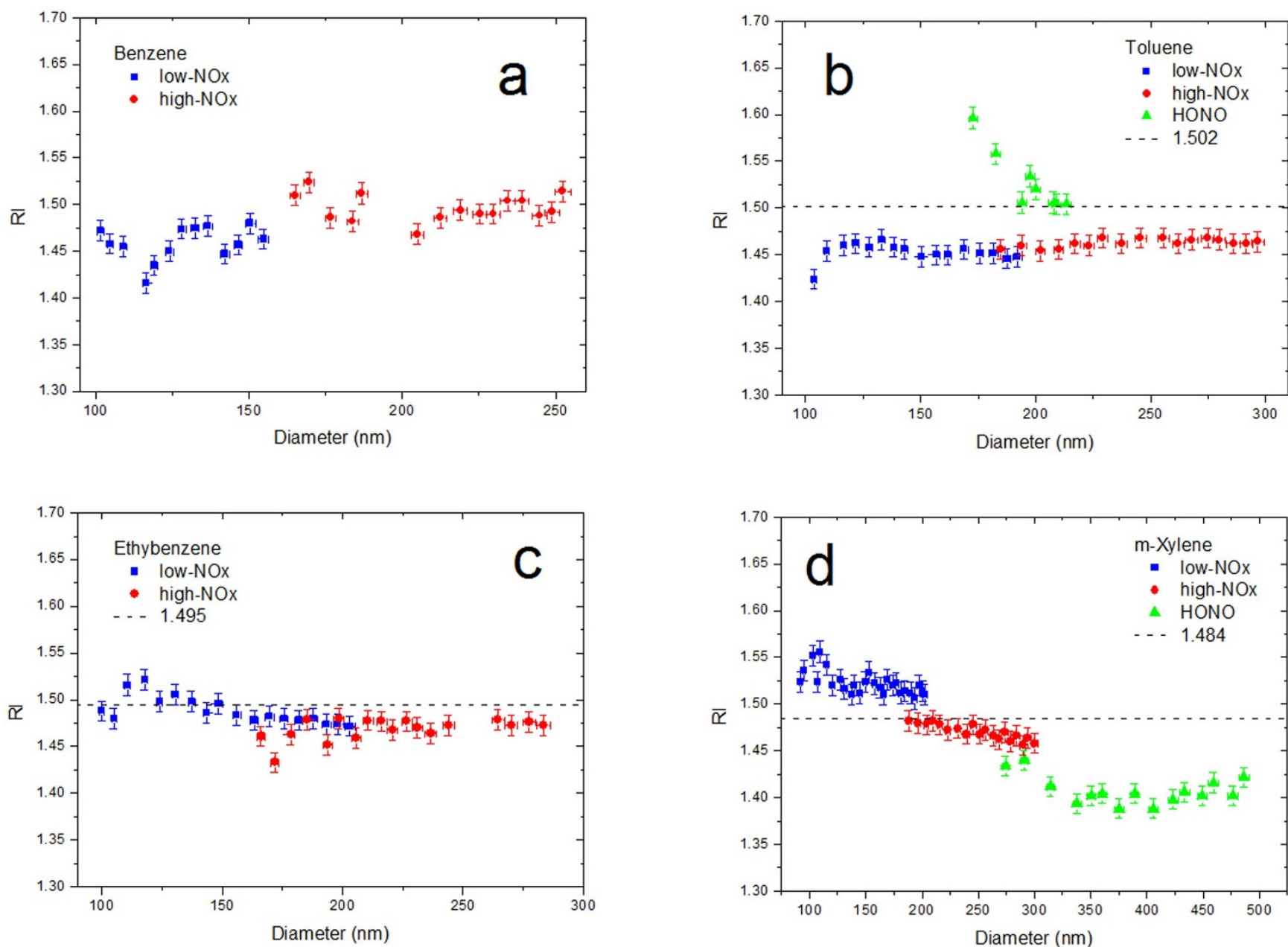

Figure $4 \mid$ Dependence of the RIs on the surface mean diameter of the SOA particles generated under different $\mathrm{NO}_{\mathrm{x}}$ levels. (a) Benzene; (b) toluene; (c) ethylbenzene; (d) $m$-xylene. The RI values calculated by the QSPR (black dashed lines) are also given in (b), (c) and (d).

a high reactivity in particle-phase reactions ${ }^{57}$. Reactions (e.g., hydration, polymerisation, formation of hemiacetal/acetal and cationic rearrangement) of gas-phase species and an aerosol surface can change the composition of the particle phase ${ }^{58}$. This effect may change the proportion of the particle components, thereby altering the RI. In addition, the ageing process might play a role in the fluctuation. For example, $m$-tolualdehyde and $m$-toluic acid are products of $m$-xylene, and $m$-tolualdehyde could be oxidised to $m$-toluic acid during the ageing process of aerosols ${ }^{52}$. According to the CRC handbook, the RIs of m-tolualdehyde and m-toluic acid are 1.541 and 1.509 , respectively ${ }^{59}$. Therefore, during this type of conversion, the RI decreases.

The dependence of the RI value on the initial $\mathrm{HC}$ and oxidiser concentrations under the low- $\mathrm{NO}_{\mathrm{x}}$ condition was also investigated. As shown in Fig. 5, the RI values decrease as the particles grow for the ethylbenzene SOA. The solid points represent the L3-L5 experiments with different concentrations of hydrogen peroxide, whereas the green (solid and open) points represent the L5 and L6 experiments with different hydrocarbon concentrations. Clearly, the oxidiser concentration does not influence the RI value under the same diameter but influences the final size mode; the hydrocarbon concentration slightly influences the RI value with a negative correlation. Generally, the different initial concentrations exert only a slight influence on the RIs.

Comparison with the model values. As illustrated in Fig. 6, we compared our experimental data to the model values. The RI values of the

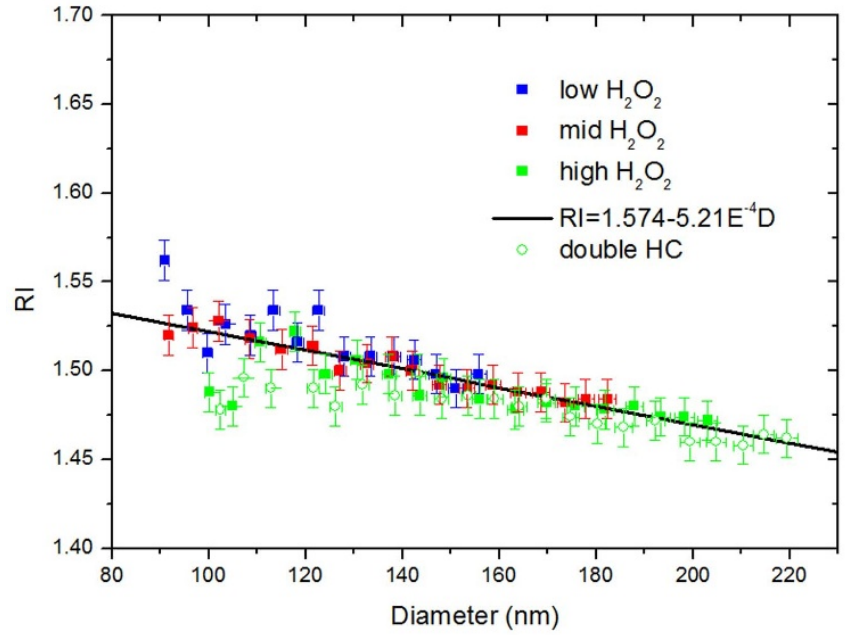

Figure 5 Dependence of the RI values on the surface mean diameter of the ethylbenzene SOA generated in the L3-L6 experiments. The solid data points represent the L3-L5 experiments with different concentrations of hydrogen peroxide, whereas the green (solid and open) data points represent the L5 and L6 experiments with different hydrocarbon concentrations. 


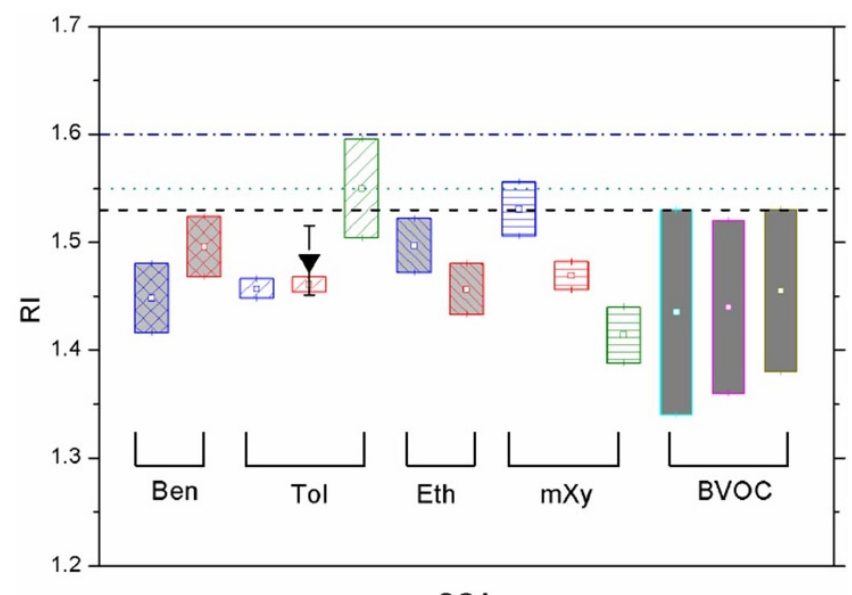

SOA

Figure $6 \mid$ RIs of the different SOA particles, and the comparison between the experimental data and the model values. The BTEX data are the current results; the toluene result (inverted triangle) is from Nakayama et $\mathrm{al}^{20}$, and the data of the BVOCs are from Kim et al. ${ }^{25-27}$. The blue boxes are the results of the low- $\mathrm{NO}_{\mathrm{x}}$ experiments; the red boxes are the results of the classical high- $\mathrm{NO}_{\mathrm{x}}$ experiments, and the green boxes are the results of the HONO experiments. The three BVOCs are limonene (cyan), $\alpha$-pinene (pink) and $\beta$-pinene (dark yellow). The three lines are the RI values of organic aerosols in different models: the blue dash/dot line is for the ULAQ; the green dotted line is for MIRAGE; and the black dashed line is for ECHAM4, GOCART, GISS, Sprintars and Grantour ${ }^{51}$.

SOA generated by BVOCs measured by Kim et al. ${ }^{24-26}$ and the data of the toluene SOA measured by Nakayama et al. ${ }^{21}$ are also shown in this figure. The three lines are the values of real RIs of seven common models ${ }^{60}$. ECHAM4, GOCART, GISS, Sprintars and Grantour perform better than ULAQ and MIRAGE compared with the laboratory studies. Nearly all of the experimental data are lower than the model values, regardless of whether the SOAs are generated by biological or anthropogenic VOCs. Kim et al. have noted that changing the RI value from 1.4 to 1.5 can produce an increase in the radiative forcing by at least $12 \%$ for non-absorbing particles $^{25}$. Because aromatic hydrocarbons, limonene, $\alpha$-pinene and $\beta$-pinene contribute most of the SOA content, current models may overestimate the RI values of organic aerosols to a certain extent.

\section{Discussion}

Our laboratory chamber results demonstrate that the RIs of the BTEX SOAs are closely related to the initial $\mathrm{NO}_{\mathrm{x}}$ concentration, with different aromatics displaying different trends. For the benzene and toluene SOAs, the RI value increases as the $\mathrm{NO}_{\mathrm{x}}$ level rises, whereas for the ethylbenzene and m-xylene SOAs, the RI value decreases correspondingly. We infer that this result is caused by the different molecular structures and the $\mathrm{RO}_{2}+\mathrm{NO}$ pathway that occurs under the high- $\mathrm{NO}_{\mathrm{x}}$ condition. The dependence of the RI value on the initial hydrocarbon and oxidant concentrations was also investigated, revealing that the initial concentrations of these reagents have little influence on the optical properties of the SOA. Under our experimental conditions (gas-phase oxidation with no seed particles), the BTEX SOAs have no obvious absorption at $532 \mathrm{~nm}$. However, the SOA particles formed under other conditions may absorb light in the visible range, and further studies examining the underlying mechanism should be performed in the future.

The RI fluctuations in relation to the level of $\mathrm{NO}_{\mathrm{x}}$ indicate that a single value for the RI of SOA is insufficient to accurately model radiative transfer. In addition, the commonly used model values for the RIs of organic aerosols are generally higher than the experimental data for the SOAs formed from both biological and anthropogenic

\begin{tabular}{|c|c|c|c|c|}
\hline Exp. No. & Parent HC & {$[\mathrm{HC}]_{0}(\mathrm{ppb})$} & {$\left[\mathrm{H}_{2} \mathrm{O}_{2}\right]_{0}(\mathrm{ppm})$} & $\mathrm{RH}(\%)$ \\
\hline Ll & benzene & 200 & 5 & $15.8-14.3$ \\
\hline L2 & toluene & 200 & 5 & $14.8-14.2$ \\
\hline L3 & ethylbenzene & 200 & 1 & $17.2-17.1$ \\
\hline L4 & ethylbenzene & 200 & 3 & $16.4-16.0$ \\
\hline L5 & ethylbenzene & 200 & 5 & $18.1-16.8$ \\
\hline L6 & ethylbenzene & 400 & 5 & $18.4-16.7$ \\
\hline L7 & $m$-xylene & 200 & 5 & $17.1-16.1$ \\
\hline
\end{tabular}

VOCs, which may cause the overestimation of direct radiative forcing of organic particles to a certain extent.

\section{Methods}

SOA formation. The rationale of the experimental design is illustrated online in Supplementary Fig. S1. The SOAs were generated in a $1 \mathrm{~m}^{3}$ Teflon smog chamber in the absence of seed particles. The temperature and $\mathrm{RH}$ were continuously monitored. The temperature was maintained at $27-29^{\circ} \mathrm{C}$, and cooling fans were in operation to prevent overheating of the chamber. The $\mathrm{RH}$ was comparatively dry (10-20\%) during the experiments. The mixing ratios of $\mathrm{NO}, \mathrm{NO}_{2}$ and $\mathrm{O}_{3}$ were monitored with Thermo $42 \mathrm{i}$ and $49 \mathrm{i}$ gas analyzers, and the concentration of the parent hydrocarbon was determined via gas chromatography with flame ionisation detection (GC-FID, Agilent 6820). The particle size distribution was measured with an SMPS, which was composed of an electrostatic classifier (EC, TSI 3080), a differential mobility analyser (DMA, TSI 3081) and a condensation particle counter (CPC, TSI 3776).

The BTEX reagents were used without further purification. Prior to each experiment, the chamber was flushed with dry, purified air several times to ensure that no detectable VOCs, $\mathrm{NO}_{\mathrm{x}}$ or $\mathrm{O}_{3}$ were present. A known volume of the parent hydrocarbon was injected into a glass U-tube and introduced into the chamber with an air stream. For the low- $\mathrm{NO}_{\mathrm{x}}$ experiments, $\mathrm{H}_{2} \mathrm{O}_{2}$ (35 wt\% water solution) was used as the $\mathrm{OH}$ precursor. The background $\mathrm{NO}_{\mathrm{x}}$ level in the chamber during the experiment was $<1 \mathrm{ppb}$, and according to the injection volume, the initial concentration of $\mathrm{H}_{2} \mathrm{O}_{2}$ was estimated to be 1-5 ppm. For the high- $\mathrm{NO}_{\mathrm{x}}$ experiments, $\mathrm{NO}_{2}$ was introduced from a $50 \mathrm{ppm}$ standard gas cylinder. In some of these experiments, HONO was added to serve as the $\mathrm{OH}$ precursor, which is similar to the method of $\mathrm{Ng}$ et al. ${ }^{19}$. To distinguish between these two conditions, we called the experiments without HONO the classical high- $\mathrm{NO}_{\mathrm{x}}$ experiments, and the others were called the HONO experiments. For the classical high- $\mathrm{NO}_{\mathrm{x}}$ experiments, the $\mathrm{NO}_{\mathrm{x}}$ concentration was $100-500 \mathrm{ppb}$, whereas for the HONO experiments, the $\mathrm{NO}_{\mathrm{x}}$ concentration was approximately $1 \mathrm{ppm}$. The HONO was prepared by the dropwise addition of $1 \mathrm{~mL}$ of $1 \mathrm{wt} \% \mathrm{NaNO}_{2}$ into $2 \mathrm{~mL}$ of $10 \mathrm{wt} \% \mathrm{H}_{2} \mathrm{SO}_{4}$ in a glass bulb. The bulb was then attached to the chamber, and a stream of dry air was passed through the bulb into the chamber. $\mathrm{NO}$ and $\mathrm{NO}_{2}$, formed as byproducts in the preparation of the HONO, were also introduced into the chamber. Additional $\mathrm{NO}_{2}$ from a $50 \mathrm{ppm}$ gas cylinder was introduced into the chamber after the addition of the HONO to achieve a total $\mathrm{NO}_{\mathrm{x}}$ level of approximately $1 \mathrm{ppm}$. The initial conditions of the low- $\mathrm{NO}_{\mathrm{x}}$ and high- $\mathrm{NO}_{\mathrm{x}}$ experiments are listed in Table 1 and Table 2, respectively.

After the parent hydrocarbon, the $\mathrm{NO}_{\mathrm{x}}$ and the $\mathrm{OH}$ precursors were placed into the chamber, and black lights were turned on to start the photoreaction. For the low- $\mathrm{NO}_{\mathrm{x}}$ experiments, a set of four lamps with a narrow peak at $254 \mathrm{~nm}$ was used, whereas for the high- $\mathrm{NO}_{\mathrm{x}}$ experiments, 36 lamps with a maximum at $365 \mathrm{~nm}$ were used.

Determination of the optical properties. The extinction coefficients of the secondary particles were measured with a custom-built cavity ring-down spectrometer (CRDS). The details of this instrument have been provided elsewhere ${ }^{5}$; therefore, it is introduced briefly in this study. The wavelength of the laser is $532 \mathrm{~nm}$. The CRDS directly provides the decay time $\tau$, and the extinction coefficient of the particles inside the cavity, $\alpha_{\text {ext }}$, can then be derived according to the following equation:

$$
a_{e x t}=\frac{L}{c l}\left(\frac{1}{\tau}-\frac{1}{\tau_{0}}\right)
$$

where $L$ is the length of the cavity (the distance between the two mirrors), $c$ is the velocity of light, $l$ is the actual distance in the cavity filled with sample and $\tau_{0}$ is the initial decay time when the cavity is filled with zero air.

For monodispersed spheres, $\alpha_{\text {ext }}$ is described by the following equation:

$$
\alpha_{\text {ext }}=C \sigma_{\text {ext }}=\frac{1}{4} C \pi D^{2} Q_{\text {ext }}
$$

where $C$ is the number concentration, $\sigma_{\text {ext }}$ is the extinction cross-section and the extinction efficiency $Q_{\text {ext }}$ is the ratio of the Beer's law extinction cross-section to the geometric area of the particle and is dimensionless.

When the particles are not monodispersed, e.g., a Gaussian distribution of particles, then $C \pi D^{2}$ in equation (3) can be replaced by the total surface concentration $S_{\text {tot }}$, and in this situation, the diameter is the surface mean diameter $D_{s m}$. Then, the equation is changed to 
Table 2 | Initial conditions of the high- $\mathrm{NO}_{\mathrm{x}}$ experiments

\begin{tabular}{|c|c|c|c|c|c|c|}
\hline Exp. No. & Parent HC & {$[\mathrm{HC}]_{0}(\mathrm{ppb})$} & {$[\mathrm{NO}]_{0}(\mathrm{ppb})$} & {$\left[\mathrm{NO}_{2}\right]_{0}(\mathrm{ppb})$} & {$\left[\mathrm{NO}_{x}\right]_{0}(\mathrm{ppb})$} & $\mathrm{RH}(\%)$ \\
\hline $\mathrm{Hl}$ & benzene $^{a}$ & 4000 & 4 & 104 & 108 & $20.2-15.1$ \\
\hline $\mathrm{H} 2$ & tolvene ${ }^{a}$ & 4000 & 39 & 398 & 437 & $15.4-12.6$ \\
\hline $\mathrm{H} 3$ & toluene ${ }^{b}$ & 230 & 213 & 925 & 1138 & $14.1-12.2$ \\
\hline $\mathrm{H} 5$ & $m$-xylene ${ }^{a}$ & 4000 & 28 & 312 & 340 & $18.7-14.0$ \\
\hline $\mathrm{H} 6$ & $m$-xylene ${ }^{b}$ & 200 & 183 & 751 & 934 & $16.1-13.9$ \\
\hline $\mathrm{H} 7$ & $m$-xylene ${ }^{b}$ & 200 & 442 & 465 & 907 & $16.2-14.8$ \\
\hline
\end{tabular}

The classical high-NO $\mathrm{NO}_{\mathrm{x}}$ experiments;

the HONO experiments.

$$
\alpha_{e x t}=\frac{1}{4} S_{t o t} Q_{e x t}=\frac{1}{4} C \pi D_{s m}^{2} Q_{e x t}
$$

$S_{t o t}$ and the $D_{s m}$ data can be obtained with the SMPS; therefore, the $Q_{e x t}$ value with different $D_{s m}$ values can be calculated using equation (4). With the $Q_{e x t}$ data, the RIs are derived using a MATLAB program.

Ultraviolet-visible light (UV-Vis) spectroscopy. The UV-Vis absorption of the SOAs was also investigated to clarify whether the aromatic SOA particles absorb light at a wavelength of $532 \mathrm{~nm}$. The SOA particles were collected with PTFE filters $\left(0.2 \mu \mathrm{m}\right.$ pore size) and extracted with $5 \mathrm{~mL}$ of a $\mathrm{CH}_{2} \mathrm{Cl}_{2}: \mathrm{CH}_{3} \mathrm{CN}(1: 1)$ solution. The filtered extracts were placed in a $1 \mathrm{~cm}$ quartz cuvette for the absorption measurements. The UV-Vis absorption spectra were obtained with a fibre optic spectrometer (Avantes 2048F) using pure solvent as the reference.

Morphology. The aerosol particles were analysed via AFM to determine their morphology. The dry, polydispersed aerosol particles were collected on $\mathrm{SiO}_{\mathrm{x}} / \mathrm{Si}(100)$ wafers. The aerosol samples were analysed at an ambient $\mathrm{RH}(\sim 40 \%)$ with a tapping mode atomic force microscope (NT-MDT Ntegra solar upright).

1. Penner, J. E., Dong, X. Q. \& Chen, Y. Observational evidence of a change in radiative forcing due to the indirect aerosol effect. Nature 427, 231-234 (2004).

2. Cowan, T., Cai, W. J., Purich, A., Rotstayn, L. \& England, M. H. Forcing of anthropogenic aerosols on temperature trends of the sub-thermocline southern Indian Ocean. Sci. Rep. 3, 2245 (2013).

3. Fyfe, J. C. et al. One hundred years of Arctic surface temperature variation due to anthropogenic influence. Sci. Rep. 3, 2645 (2013).

4. Chand, D., Wood, R., Anderson, T. L., Satheesh, S. K. \& Charlson, R. J. Satellitederived direct radiative effect of aerosols dependent on cloud cover. Nat. Geosci. 2, 181-184 (2009).

5. Wang, L., Wang, W. \& Ge, M. Extinction efficiencies of mixed aerosols measured by aerosol cavity ring down spectrometry. Chinese Sci. Bull. 57, 2567-2573 (2012).

6. Zarzana, K. J., De Haan, D. O., Freedman, M. A., Hasenkopf, C. A. \& Tolbert, M. A. Optical properties of the products of alpha-dicarbonyl and amine reactions in simulated cloud droplets. Environ. Sci. Technol. 46, 4845-4851 (2012).

7. Zhang, Q. et al. Ubiquity and dominance of oxygenated species in organic aerosols in anthropogenically-influenced Northern Hemisphere midlatitudes. Geophys. Res. Lett. 34, L13801 (2007).

8. Davidson, C. I., Phalen, R. F. \& Solomon, P. A. Airborne particulate matter and human health: A review. Aerosol Sci. Tech. 39, 737-749 (2005).

9. Eldering, A. \& Cass, G. R. Source-oriented model for air pollutant effects on visibility. J. Geophys. Res. 101, 19343-19369 (1996).

10. Turpin, B. J. \& Huntzicker, J. J. Identification of secondary organic aerosol episodes and quantitation of primary and secondary organic aerosol concentrations during SCAQS. Atmos. Environ. 29, 3527-3544 (1995).

11. Singh, H. B., Salas, L. J., Cantrell, B. K. \& Redmond, R. M. Distribution of aromatic hydrocarbons in the ambient air. Atmos. Environ. 19, 1911-1919 (1985).

12. Zi-feng, L., Ji-ming, H. A. O., Jing-chun, D. \& Jun-hua, L. I. Estimate of the formation potential of secondary organic aerosol in Beijing summertime. Huan Jing Ke Xue 30, 969-975 (2009).

13. Pandey, S. K. et al. Long-term study of NOx behavior at urban roadside and background locations in Seoul, Korea. Atmos. Environ. 42, 607-622 (2008).

14. Gardner, M. W. \& Dorling, S. R. Neural network modelling and prediction of hourly NOx and NO2 concentrations in urban air in London. Atmos. Environ. 33, 709-719 (1999).

15. Clapp, L. J. \& Jenkin, M. E. Analysis of the relationship between ambient levels Of $\mathrm{O}-3, \mathrm{NO} 2$ and $\mathrm{NO}$ as a function of NO chi in the UK. Atmos. Environ. 35 6391-6405 (2001).

16. Johnson, D., Jenkin, M. E., Wirtz, K. \& Martin-Reviejo, M. Simulating the Formation of Secondary Organic Aerosol from the Photooxidation of Toluene. Environ. Chem. 1, 150-165 (2004).

17. Johnson, D., Jenkin, M. E., Wirtz, K. \& Martin-Reviejo, M. Simulating the Formation of Secondary Organic Aerosol from the Photooxidation of Aromatic Hydrocarbons. Environ. Chem. 2, 35-48 (2005).
18. Ng, N. L. et al. Effect of $\mathrm{NO}(\mathrm{x})$ level on secondary organic aerosol (SOA) formation from the photooxidation of terpenes. Atmos. Chem. Phys. 7, 5159-5174 (2007).

19. Ng, N. L. et al. Secondary organic aerosol formation from m-xylene, toluene, and benzene. Atmos. Chem. Phys. 7, 3909-3922 (2007).

20. Hallquist, M. et al. The formation, properties and impact of secondary organic aerosol: current and emerging issues. Atmos. Chem. Phys. 9, 5155-5236 (2009).

21. Nakayama, T. et al. Laboratory studies on optical properties of secondary organic aerosols generated during the photooxidation of toluene and the ozonolysis of $\alpha$ pinene. J. Geophys. Res. 115, D24204 (2010).

22. Nakayama, T. et al. Wavelength and NOx dependent complex refractive index of SOAs generated from the photooxidation of toluene. Atmos. Chem. Phys. 13, 531-545 (2013).

23. Redmond, H. \& Thompson, J. E. Evaluation of a quantitative structure-property relationship (QSPR) for predicting mid-visible refractive index of secondary organic aerosol (SOA). Phys. Chem. Chem. Phys. 13, 6872-6882 (2011).

24. Kim, H., Barkey, B. \& Paulson, S. E. Real refractive indices of $\alpha$ - and $\beta$-pinene and toluene secondary organic aerosols generated from ozonolysis and photooxidation. J. Geophys. Res. 115, D24212 (2010).

25. Kim, H., Barkey, B. \& Paulson, S. E. Real refractive indices and formation yields of secondary organic aerosol generated from photooxidation of limonene and alphapinene: the effect of the $\mathrm{HC} / \mathrm{NO}(\mathrm{x})$ ratio. J. Phys. Chem. A 116, 6059-6067 (2012).

26. Kim, H. \& Paulson, S. E. Real refractive indices and volatility of secondary organic aerosol generated from photooxidation and ozonolysis of limonene, $\alpha$-pinene and toluene. Atmos. Chem. Phys. 13, 7711-7723 (2013).

27. Yu, Y. et al. Photooxidation of $\alpha$-pinene at high relative humidity in the presence of increasing concentrations of NOx. Atmos. Environ. 42, 5044-5060 (2008).

28. Geng, F. et al. Characterizations of ozone, NOx, and VOCs measured in Shanghai, China. Atmos. Environ. 42, 6873-6883 (2008).

29. Zhang, Y., Mu, Y., Liu, J. \& Mellouki, A. Levels, sources and health risks of carbonyls and BTEX in the ambient air of Beijing, China. J. Environ. Sci. 24, 124-130 (2012)

30. Liu, J., Zhang, X.-l., Xu, X.-f. \& Xu, H.-h. Comparison analysis of variation characteristics of SO2, NOx, O3 and PM2.5 between rural and urban areas, Beijing. Huan Jing Ke Xue 29, 1059-1065 (2008).

31. Grant, D. D. et al. Volatile organic compounds at a rural site in western Senegal. J. Atmos. Chem. 60, 19-35 (2008).

32. Rohrer, F. et al. Mixing ratios and photostationary state of $\mathrm{NO}$ and $\mathrm{NO} 2$ observed during the POPCORN field campaign at a rural site in Germany. J. Atmos. Chem. 31, 119-137 (1998).

33. McMurry, P. H. \& Grosjean, D. Gas and aerosol wall losses in teflon film smog chambers. Environ. Sci. Technol. 19, 1176-1182 (1985).

34. Martin-Reviejo, M. \& Wirtz, K. Is benzene a precursor for secondary organic aerosol? Environ. Sci. Technol. 39, 1045-1054 (2005).

35. Freedman, M. A., Baustian, K. J., Wise, M. E. \& Tolbert, M. A. Characterizing the morphology of organic aerosols at ambient temperature and pressure. Anal. Chem. 82, 7965-7972 (2010).

36. Marcolli, C., Luo, B. P. \& Peter, T. Mixing of the organic aerosol fractions: Liquids as the thermodynamically stable phases. J. Phys. Chem. A 108, 2216-2224 (2004).

37. Bahreini, R. et al. Measurements of secondary organic aerosol from oxidation of cycloalkenes, terpenes, and m-xylene using an Aerodyne aerosol mass spectrometer. Environ. Sci. Technol. 39, 5674-5688 (2005).

38. Kirchstetter, T. W., Novakov, T. \& Hobbs, P. V. Evidence that the spectral dependence of light absorption by aerosols is affected by organic carbon. J. Geophys. Res. 109, D21208 (2004).

39. Barnard, J. C., Volkamer, R. \& Kassianov, E. I. Estimation of the mass absorption cross section of the organic carbon component of aerosols in the Mexico City Metropolitan Area. Atmos. Chem. Phys. 8, 6665-6679 (2008).

40. Volkamer, R., Ziemann, P. J. \& Molina, M. J. Secondary Organic Aerosol Formation from Acetylene ( $\mathrm{C} 2 \mathrm{H} 2)$ : seed effect on $\mathrm{SOA}$ yields due to organic photochemistry in the aerosol aqueous phase. Atmos. Chem. Phys. 9, 1907-1928 (2009).

41. Shapiro, E. L. et al. Light-absorbing secondary organic material formed by glyoxal in aqueous aerosol mimics. Atmos. Chem. Phys. 9, 2289-2300 (2009). 
42. Sareen, N., Schwier, A. N., Shapiro, E. L., Mitroo, D. \& McNeill, V. F. Secondary organic material formed by methylglyoxal in aqueous aerosol mimics. Atmos. Chem. Phys. 10, 997-1016 (2010)

43. Gelencser, A. et al. In-situ formation of light-absorbing organic matter in cloud water. J. Atmos. Chem. 45, 25-33 (2003).

44. Chang, J. L. \& Thompson, J. E. Characterization of colored products formed during irradiation of aqueous solutions containing $\mathrm{H} 2 \mathrm{O} 2$ and phenolic compounds. Atmos. Environ. 44, 541-551 (2010).

45. Ervens, B., Turpin, B. J. \& Weber, R. J. Secondary organic aerosol formation in cloud droplets and aqueous particles (aqSOA): a review of laboratory, field and model studies. Atmos. Chem. Phys. 11, 11069-11102 (2011).

46. Limbeck, A., Kulmala, M. \& Puxbaum, H. Secondary organic aerosol formation in the atmosphere via heterogeneous reaction of gaseous isoprene on acidic particles. Geophys. Res. Lett. 30, 19 (2003).

47. Bones, D. L. et al. Appearance of strong absorbers and fluorophores in limonene$\mathrm{O}-3$ secondary organic aerosol due to $\mathrm{NH} 4+-$-mediated chemical aging over long time scales. J. Geophys. Res. 115, D05203 (2010).

48. Liu, P. F., Zhang, Y. \& Martin, S. T. Complex Refractive Indices of Thin Films of Secondary Organic Materials by Spectroscopic Ellipsometry from 220 to 1200 nm. Environ. Sci. Technol. 47, 13594-13601 (2013).

49. Song, C., Gyawali, M., Zaveri, R. A., Shilling, J. E. \& Arnott, W. P. Light absorption by secondary organic aerosol from alpha-pinene: Effects of oxidants, seed aerosol acidity, and relative humidity. J. Geophys. Res. 118, 11741-11749 (2013).

50. Bohren, C. F. \& Huffman, D. R. Absorption and Scattering of Light by Small Particles. (John Wiley, 1983).

51. Atkinson, R. Atmospheric chemistry of VOCs and NOx. Atmos. Environ. 34, 2063-2101 (2000).

52. Forstner, H. J. L., Flagan, R. C. \& Seinfeld, J. H. Secondary organic aerosol from the photooxidation of aromatic hydrocarbons: Molecular composition. Environ. Sci. Technol. 31, 1345-1358 (1997).

53. Moreels, E., Degreef, C. \& Finsy, R. Laser-light refractometer. Appl. Optics 23, 3010-3013 (1984)

54. Liu, Y. \& Daum, P. H. Relationship of refractive index to mass density and selfconsistency of mixing rules for multicomponent mixtures like ambient aerosols. J. Aerosol Sci. 39, 974-986 (2008).

55. Malloy, Q. G. J. et al. Real-time aerosol density determination utilizing a modified scanning mobility particle sizer-aerosol particle mass analyzer system. Aerosol Sci. Tech. 43, 673-678 (2009)

56. Qi, L., Nakao, S., Tang, P. \& Cocker, D. R., III. Temperature effect on physical and chemical properties of secondary organic aerosol from $\mathrm{m}$-xylene photooxidation. Atmos. Chem. Phys. 10, 3847-3854 (2010).

57. Smith, D. F., Kleindienst, T. E. \& McIver, C. D. Primary product distributions from the reaction of $\mathrm{OH}$ with $\mathrm{m}$-, p-xylene, 1,2,4- and 1,3,5-trimethylbenzene. J. Atmos. Chem. 34, 339-364 (1999).
58. Cao, G. \& Jang, M. Effects of particle acidity and UV light on secondary organic aerosol formation from oxidation of aromatics in the absence of NOx. Atmos Environ. 41, 7603-7613 (2007).

59. David R. Lide, ed., CRC Handbook of Chemistry and Physics, Internet Version 2005. <http://www.hbcpnetbase.com>, (CRC Press, 2005) Date of access: 09/01/ 2014

60. Kinne, S. et al. Monthly averages of aerosol properties: A global comparison among models, satellite data, and AERONET ground data. J. Geophys. Res. 108 D20 (2003).

\section{Acknowledgments}

This project was supported by the Strategic Priority Research Program (B) of the Chinese Academy of Sciences (Grant No. XDB05010400), the National Basic Research Program of China (973 Program, No. 2011CB403401), the Ministry of Science and Technology of China and the National Natural Science Foundation of China (Major Program: 21190052, Contract No. 40925016, 41173112, 41227805)

\section{Author contributions}

M.G., W.W. and K.L. authored the manuscript. M.G., W.W. and K.L. designed the study. J.L. and D.W. contributed the morphology data. All five authors performed the experiments. M.G., W.W. and K.L. analysed the data.

\section{Additional information}

Supplementary information accompanies this paper at http://www.nature.com/ scientificreports

Competing financial interests: The authors declare no competing financial interests.

How to cite this article: Li, K., Wang, W.G., Ge, M.F., Li, J.J. \& Wang, D. Optical properties of secondary organic aerosols generated by photooxidation of aromatic hydrocarbons. Sci. Rep. 4, 4922; DOI:10.1038/srep04922 (2014).

This work is licensed under a Creative Commons Attribution-NonCommercialNoDerivs 3.0 Unported License. The images in this article are included in the article's Creative Commons license, unless indicated otherwise in the image credit; if the image is not included under the Creative Commons license, users will need to obtain permission from the license holder in order to reproduce the image. To view a copy of this license, visit http://creativecommons.org/licenses/by-nc-nd/3.0/ 